\title{
From disease modelling to personalised therapy in patients
}

\section{with CEP290 mutations [version 1; peer review: 2 approved]}

\author{
Elisa Molinari (D1, Shalabh Srivastava1, John A. Sayer (D1,2, Simon A. Ramsbottom¹ \\ ${ }^{1}$ Institute of Genetic Medicine, Newcastle University, Newcastle, NE1 3BZ, UK \\ ${ }^{2}$ Renal Services, Newcastle upon Tyne NHS Foundation Trust, Newcastle, NE7 7DN, UK
}

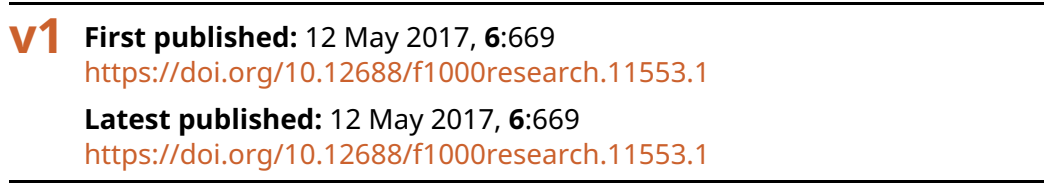

\section{Abstract}

Mutations that give rise to premature termination codons are a common cause of inherited genetic diseases. When transcripts containing these changes are generated, they are usually rapidly removed by the cell through the process of nonsense-mediated decay. Here we discuss observed changes in transcripts of the centrosomal protein CEP290 resulting not from degradation, but from changes in exon usage. We also comment on a landmark paper (Drivas et al. Sci Transl Med. 2015) where modelling this process of exon usage may be used to predict disease severity in CEP290 ciliopathies, and how understanding this process may potentially be used for therapeutic benefit in the future.

\section{Keywords}

Cep290, splicing, genetic pleiotropy, exon-skipping, Leber congential amaurosis, Joubert syndrome, nephronophthisis

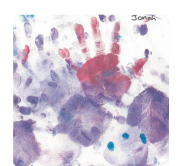

This article is included in the Rare diseases

collection.

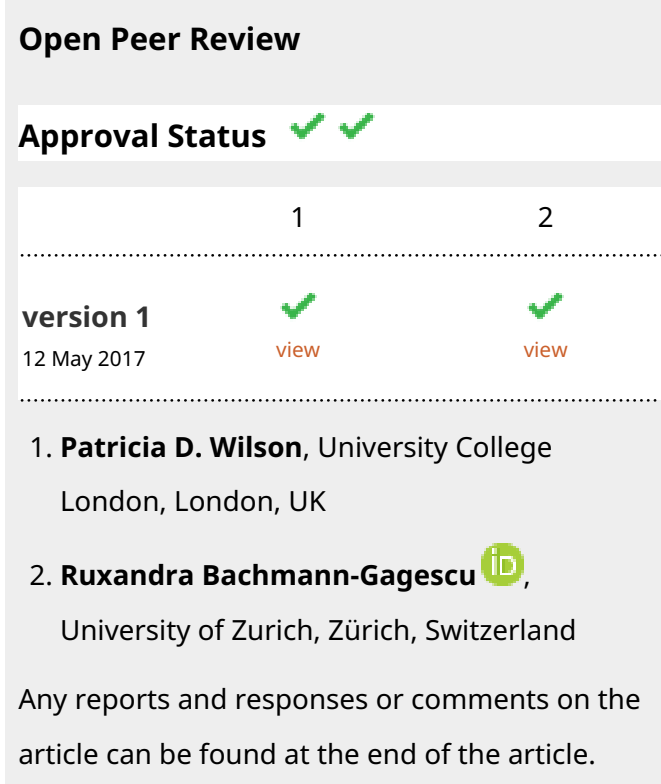


Corresponding author: Simon A. Ramsbottom (Simon.Ramsbottom@newcastle.ac.uk)

Competing interests: No competing interests were disclosed.

Grant information: E.M. is funded by Kids Kidney Research. J.A.S is funded by the Medical Research Council (MR/M012212/1) and the Newcastle upon Tyne Hospitals NHS Charity. S.S. and S.A.R are funded by Kidney Research UK (PDF_003_20151124).

The funders had no role in study design, data collection and analysis, decision to publish, or preparation of the manuscript.

Copyright: $\odot 2017$ Molinari E et al. This is an open access article distributed under the terms of the Creative Commons Attribution License, which permits unrestricted use, distribution, and reproduction in any medium, provided the original work is properly cited.

How to cite this article: Molinari E, Srivastava S, Sayer JA and Ramsbottom SA. From disease modelling to personalised therapy in patients with CEP290 mutations [version 1; peer review: 2 approved] F1000Research 2017, 6:669

https://doi.org/10.12688/f1000research.11553.1

First published: 12 May 2017, 6:669 https://doi.org/10.12688/f1000research.11553.1 


\section{Mechanisms of aberrant transcript removal}

Nonsense mutations are changes to the coding sequence of a gene, which lead to a termination (stop) codon being coded for in place of an amino acid, giving rise to a truncated protein. These types of mutations are common in human disease and account for around a third of inherited genetic disorders ${ }^{1}$. The resultant abnormally truncated proteins can have significant deleterious effects on the cell. A truncated protein may display a loss-of-function or in some cases a dominant-negative function that can seriously impact on normal biological processes. Two mechanisms have been identified by which cells remove unwanted transcripts, thereby avoiding production of abnormal protein. The first of these is nonsense-mediated decay (NMD), whereby transcripts containing a nonsense mutation are targeted for degradation giving rise to a reduction in transcript $t^{2,3}$. The second method that has been described is that of nonsenseassociated altered splicing (NAS), a mechanism that promotes the increase in transcripts that are missing the exon containing the deleterious mutation ${ }^{4}$.

Many genes are alternately spliced in order to generate proteins with unique properties and functions ${ }^{5}$. However, NAS, triggered by the presence of a premature stop codon, leads to splicing of an exon that may not normally be spliced. Evidence of NAS has been shown following mutation of $C E P 290^{6}$, a gene that, when mutated, is associated with a spectrum of inherited genetic disorders, including Leber congenital amaurosis (LCA), Senior Løken syndrome (SLS), Joubert syndrome (JBTS) and Meckel-Gruber syndrome ${ }^{7-10}$. The compound heterozygous mutations described in a family with LCA by Littink et al. included a novel premature termination codon in exon 7 (c.451C>T, p.Arg 151*). When mRNA transcripts were sequenced, skipping of either exon 7 alone, or exon 7 and exon 8 was revealed, which was never seen in controls ${ }^{6}$. The authors concluded that the LCA phenotype seen in the patient, which was less severe than expected, was due to a functional CEP290 protein being produced due to NAS. The genetic pleiotropy exhibited in patients with CEP290 mutations may therefore be explained in part by the differential ability of NAS to give rise to a functional protein in the event of a premature termination codon being generated. One can surmise that the greater the level of near-normal (wild-type) protein that can be generated, the lower the disease burden and the milder the phenotype.

\section{Predicting disease severity using alternate splicing models}

The recent landmark article by Drivas et al. has provided some novel insights into the potential modelling of CE290 mutations, based around the idea that genetic pleiotropy may arise as a result of differences in protein levels ${ }^{11}$. Known mutations in CEP290 were classified into categories based on the premise that the severity of disease correlates with the impact on the overall level of functional protein that may be generated. Missense mutations were classified as mild, as they should impact less on the level of transcript, whereas nonsense mutations were either moderate or severe depending on whether or not they occur in a codon that begins and ends in the same frame and can therefore be spliced out with no change in reading frame. In theory, transcripts containing nonsense mutations would be removed by NMD, so the overall level of CEP290 transcript would be lower in those patients harbouring mutations in exons that may not be easily skipped by NAS. Using this simple model, it was shown that the disease severity does correlate fairly well with the predicted level of CEP290 protein. The authors then modified the model to take into account skipping of regions of known functional importance. Mutations that map to these regions have more severe phenotypes than can be explained by the original model, due to the fact that skipping out these exons gives rise to a protein with reduced functionality.

When the model was tested against genotype-phenotype correlations in patients with varying symptoms, it did appear to accurately predict the phenotype from the given genotype ${ }^{11}$. Furthermore, the authors showed that for mutations that give rise to a premature termination codon, the exon in which the mutation has occurred is indeed spliced out, as would be expected if NAS were activated. However, what was unexpected was that in control samples these exons were also shown to be spliced out. Perhaps even more surprisingly, the spliced levels observed in control samples were a similar level to that of the patient samples. The fact that the levels observed in controls are the same as seen in patients suggests that it is in fact not NAS that is leading to splicing of these exons; splicing is simply happening at a basal level and is not in any way increased due to the presence of the mutation.

Importantly, while it was shown by PCR that small amounts of these transcripts existed, the authors were unable to detect transcripts arising from basal exon skipping via direct RNA-sequencing, which suggests the infrequent nature of these alternative splicing events and so brings into question the biological relevance of this mechanism. It must also be noted that there are patients who have the same or similar mutations, but present with symptoms of differing severity. One reported CEP290 mutation (c.21G>T; p.Trp7Cys) gives rise to both SLS and JBTS phenotypes ${ }^{8,9}$. This mutation is in exon 2, which contains the start codon, and so may not be spliced out. In this case, the genotype alone is unable to be used to predict how the transcript level will impact on the severity of the disease and is therefore no use as a proxy measure for phenotype. Similarly, there have been several patients reported with a nonsense mutation in exon 36 (c.4723A>T; p.1575*), who present with LCA and not JBTS $^{12-14}$, even though this mutation is only a few bases upstream of the c.4732G $>$ T; p.Glu1578* mutation with JBTS phenotypes ${ }^{8}$. It must therefore be acknowledged that exon skipping is not the sole source of genetic pleiotropy.

\section{Manipulation of splicing for therapeutic benefit}

Patients suffering from non-syndromic LCA commonly have a mutation within the CEP290 gene (c.2991+1655A>G), which creates a cryptic splice site, resulting in the inclusion of an aberrant exon of 128 bp that contains a premature stop codon (p.Cys998*). Alternative splicing of the cryptic exon occurs in some, but not all, mRNA transcripts ${ }^{15,16}$. Collin et al. successfully exploited the use of antisense oligonucleotides (AONs) to boost an efficient skipping of the mutant cryptic exon: by transfecting AONs in patientderived lymphoblastoid cells, they were able to redirect normal splicing of $C E P 290^{17}$. As a proof of principle for the feasibility of altering the splicing pattern of Cep290 in vivo in the affected tissue, intravitreal injection of wild type mice with naked spliceswitching AON led to the modification of Cep290 splicing in 
retinal cells ${ }^{18}$. Similarly, naked AONs and adeno-associated virus-packaged AONs were administered to a humanized mouse model (Cep290 ${ }^{\text {lcallca }}$ ) that contains intron 26 of the human CEP290 gene carrying the c. $2991+1655 \mathrm{~A}>\mathrm{G}$ mutation. Delivery by intraocular injection caused a statistically significant reduction of aberrantly spliced Cep290 up to 1 month after injection, without compromising the retinal structure ${ }^{19}$. However, humanized Cep290 lcalca mouse fails to recapitulate the human clinical features, making it impossible to understand the actual impact of AONdirected restoration of wild type Cep290 transcript on the retinal phenotype $^{18-20}$. Nevertheless, the ability of splice-switching AONs not only to cause an upregulation of wild type CEP290 mRNA to normal levels, but also to restore otherwise impaired ciliogenesis in patient-derived fibroblast cells, demonstrates, although only in a limited way, that an increase of correctly spliced transcript can indeed result in a phenotypical rescue ${ }^{21}$.

Using a similar approach, AONs can be exploited to promote skipping of exons carrying nonsense mutations to increase the abundance of slightly shortened transcripts and near-full length functional protein, as in the case of mutated dystrophin in Duchenne muscular dystrophy ${ }^{22}$.

The majority of CEP290 mutations are nonsense mutations that introduce a premature stop codon in the $\mathrm{mRNA}^{9}$. In addition to retinal degeneration, these mutations cause a wide spectrum of multisystemic ciliopathies, such as the cystic kidney disease nephronophthisis, which results in end stage renal failure at a median age of 13 years. Due to the relatively slow progression of this disease, there is a potential time for therapeutic intervention. If CEP290 protein levels could be restored by inducing exon skipping, disease progression may be significantly slowed or even halted. As we move closer to personalised medicine, especially in the arena of rare disease, it is likely that therapeutic strategies such as this may become routine, with unique therapies being designed based on the patient's genotype. Understanding the way in which deleterious mutations are dealt with in vivo will have a significant impact on how successfully these therapies can be implemented.

\section{Author contributions}

J.A.S conceived the article. S.A.R, S.S and E.M prepared the first draft. All authors contributed to the revision of the draft manuscript and have agreed to the final content.

\section{Competing interests}

No competing interests were disclosed.

\section{Grant information}

E.M. is funded by Kids Kidney Research. J.A.S is funded by the Medical Research Council (MR/M012212/1) and the Newcastle upon Tyne Hospitals NHS Charity. S.S. and S.A.R are funded by Kidney Research UK (PDF_003_20151124).

The funders had no role in study design, data collection and analysis, decision to publish, or preparation of the manuscript.
1. Frischmeyer PA, Dietz HC: Nonsense-mediated mRNA decay in health and disease. Hum Mol Genet. 1999; 8(10): 1893-900. PubMed Abstract | Publisher Full Text

2. Kurosaki T, Maquat LE: Nonsense-mediated mRNA decay in humans at a glance. J Cell Sci. 2016; 129(3): 461-7. PubMed Abstract | Publisher Full Text | Free Full Text

3. Khajavi M, Inoue K, Lupski JR: Nonsense-mediated mRNA decay modulates clinical outcome of genetic disease. Eur J Hum Genet. 2006; 14(10): 1074-81. PubMed Abstract | Publisher Full Text

4. Wang J, Chang YF, Hamilton JI, et al.: Nonsense-associated altered splicing: a frame-dependent response distinct from nonsense-mediated decay. Mol Cell. 2002; 10(4): 951-7.

PubMed Abstract | Publisher Full Text

5. de Klerk E, 't Hoen PA: Alternative mRNA transcription, processing, and translation: insights from RNA sequencing. Trends Genet. 2015; 31(3): 128-39. PubMed Abstract | Publisher Full Text

6. Littink KW, Pott JW, Collin RW, et al: A novel nonsense mutation in CEP290 induces exon skipping and leads to a relatively mild retinal phenotype. Invest Ophthalmol Vis Sci. 2010; 51(7): 3646-52. PubMed Abstract | Publisher Full Text

7. Sayer JA, Otto EA, O'Toole JF, et al:: The centrosomal protein nephrocystin-6 is mutated in Joubert syndrome and activates transcription factor ATF4. Nat Genet. 2006; 38(6): 674-81.

PubMed Abstract | Publisher Full Text

8. Valente EM, Silhavy JL, Brancati F, et al:: Mutations in CEP290, which encodes a centrosomal protein, cause pleiotropic forms of Joubert syndrome. Nat Genet. 2006; 38(6): 623-5.

PubMed Abstract | Publisher Full Text
9. Coppieters F, Lefever S, Leroy BP, et al.: CEP290, a gene with many faces: mutation overview and presentation of CEP290base. Hum Mutat. 2010; 31(10): 1097-108.

PubMed Abstract | Publisher Full Text

10. Frank V, den Hollander Al, Brüchle NO, et al.: Mutations of the CEP290 gene encoding a centrosomal protein cause Meckel-Gruber syndrome. Hum Mutat. 2008; 29(1): 45-52.

PubMed Abstract | Publisher Full Text

11. Drivas TG, Wojno AP, Tucker BA, et al.: Basal exon skipping and genetic pleiotropy: A predictive model of disease pathogenesis. Sci Trans/ Med. 2015; 7(291): 291ra97.

PubMed Abstract | Publisher Full Text | Free Full Text

12. Perrault I, Delphin N, Hanein S, et al.: Spectrum of NPHP6/CEP290 mutations in Leber congenital amaurosis and delineation of the associated phenotype. Hum Mutat. 2007; 28(4): 416.

PubMed Abstract | Publisher Full Text

13. Brancati $F$, Barrano G, Silhavy JL, et al.: CEP290 mutations are frequently identified in the oculo-renal form of Joubert syndrome-related disorders. $A m \mathrm{~J}$ Hum Genet. 2007; 81(1): 104-13.

PubMed Abstract | Publisher Full Text | Free Full Text

14. Stone EM: Leber congenital amaurosis - a model for efficient genetic testing of heterogeneous disorders: LXIV Edward Jackson Memorial Lecture. Am J Ophthalmol. 2007; 144(6): 791-811. PubMed Abstract | Publisher Full Text

15. den Hollander Al, Koenekoop RK, Yzer S, et al:: Mutations in the CEP290 (NPHP6) gene are a frequent cause of Leber congenital amaurosis. Am J Hum Genet. 2006; 79(3): 556-61.

PubMed Abstract | Publisher Full Text | Free Full Text 
16.

den Hollander AI, Roepman R, Koenekoop RK, et al.: Leber congenital amaurosis: genes, proteins and disease mechanisms. Prog Retin Eye Res. 2008; 27(4): 391-419.

PubMed Abstract | Publisher Full Text

17. Collin RW, den Hollander Al, van der Velde-Visser SD, et al:: Antisense Oligonucleotide (AON)-based Therapy for Leber Congenital Amaurosis Caused by a Frequent Mutation in CEP290. Mol Ther Nucleic Acids. 2012; 1: e14. PubMed Abstract | Publisher Full Text | Free Full Text

18. Gerard X, Perrault I, Munnich A, et al.: Intravitreal Injection of Splice-switching Oligonucleotides to Manipulate Splicing in Retinal Cells. Mol Ther Nucleic Acids. 2015; 4: e250.

PubMed Abstract | Publisher Full Text | Free Full Text

19. Garanto A, Chung DC, Duijkers L, et al:: In vitro and in vivo rescue of aberrant splicing in CEP290-associated LCA by antisense oligonucleotide delivery.
Hum Mol Genet. 2016; 25(12): 2552-63. PubMed Abstract | Publisher Full Text

20. Garanto A, van Beersum SE, Peters TA, et al.: Unexpected CEP290 mRNA splicing in a humanized knock-in mouse model for Leber congenital amaurosis. PLoS One. 2013; 8(11): e79369.

PubMed Abstract | Publisher Full Text | Free Full Text

21. Gerard X, Perrault I, Hanein S, et al:: AON-mediated Exon Skipping Restores Ciliation in Fibroblasts Harboring the Common Leber Congenital Amaurosis CEP290 Mutation. Mol Ther Nucleic Acids. 2012; 1: e29.

PubMed Abstract | Publisher Full Text | Free Full Text

22. Wilton SD, Fall AM, Harding PL, et al:: Antisense oligonucleotide-induced exon skipping across the human dystrophin gene transcript. Mol Ther. 2007; 15(7): 1288-96.

PubMed Abstract | Publisher Full Text 


\section{Open Peer Review}

\section{Current Peer Review Status:}

\section{Version 1}

Reviewer Report 19 June 2017

https://doi.org/10.5256/f1000research.12479.r23067

(C) 2017 Bachmann-Gagescu R. This is an open access peer review report distributed under the terms of the Creative Commons Attribution License, which permits unrestricted use, distribution, and reproduction in any medium, provided the original work is properly cited.

\section{Ruxandra Bachmann-Gagescu}

Institute for Molecular Life Sciences, Institute of Medical Genetics, University of Zurich, Zürich, Switzerland

The correspondence article by Molinari and colleagues discusses potential therapeutic options through manipulation of splicing for patients harbouring CEP290 mutations. This represents an important topic given the role of CEP290 in human disease and the intense research focusing on understanding the phenotypic consequences of CEP290 dysfunction and identifying therapies for affected individuals. Thus the rationale for writing this correspondence article is clearly established.

The article by Molinari and colleagues reviews various studies that have provided a possible explanation to the important phenotypic pleiotropy caused by CEP290 mutations through exon skipping to by-pass stop mutations ("non-sense associated altered splicing"). In particular, they thoroughly comment on the paper by Drivas et al. who developed an algorithm to predict phenotypic severity based on the location of the mutation within the CEP290 gene and consequent anticipated CEP290 protein levels. After discussing this model in depth, Molinari and colleagues suggest that targeted modulation of splicing through antisense oligonucleotide-based therapy is an interesting therapeutic option for patients with CEP290 mutations.

The opinions expressed in this correspondence article are well balanced and supported by appropriate citations. The authors thoroughly comment on the study by Drivas et al, highlighting strengths but also discussing limitations. In particular, they comment on the fact that exon skipping appears to mostly occur not through "nonsense-associated altered splicing" as expected but rather through "basal exon skipping" independently of the presence of a mutation. While this finding questions the relevance of exon skipping occurring in vivo in the presence of stop mutations, it would probably not question the feasibility of splicing modulation as a therapeutic modality; increasing the proportion of transcript by-passing the mutation should partially rescue protein function, regardless of whether such a mechanism is triggered in vivo to attenuate consequences of a mutations on protein function. 
Besides these considerations, one important point that is not addressed in the work by Drivas et al , but that is appropriately raised by Molinari and colleagues, is the fact that phenotypic differences are observed even between individuals sharing the same causal mutations, indicating that other mechanisms must influence the phenotypic outcome. Similarly, our recent work on a large JS cohort (Phelps et al, Genetics in Medicine in press) noted phenotypic discrepancies despite identical causal mutations in $60 \%$ of situations. Therefore, while the causal mutations certainly play a major role in determining the phenotypic outcome, additional mechanisms must also underlie the genetic pleiotropy observed.

The discussion by Molinari and colleagues could have been expanded to include additional points: In commenting on the work by Drivas et al, it should be pointed out that the correlation between the anticipated protein levels and the phenotypic severity is strongly influenced by the phenotypic assessment. The study by Drivas et al mostly relied on phenotypic descriptions from the literature and misclassification of patients (as having JS instead of JSRD for example, if no thorough assessments of retinal or renal function were performed) cannot be ruled out. Moreover, determining the "phenotypic severity" is more difficult than it seems. The commonly used scale considers LCA as the least severe disease manifestation, MKS as the most severe and JS with or without additional features in-between. However, one can argue whether single-organ involvement resulting in blindness in early childhood (LCA) is really less severe than presence of the molar tooth sign with mild developmental delay (classified as JS) or whether JS with mild developmental delay and polydactyly (classified as JSRD) is more severe than JS with severe developmental delay but no additional organ system involvement (classified as JS). From a biological standpoint, it remains yet to be demonstrated that the degree of dysfunction of a given protein is necessarily correlated with the number of tissues affected. One could provide alternative hypotheses involving the presence of additional variants in other genes (modifiers) or suggesting that different regions of the protein are important for different functions in different cell types. These points might affect the reliability of the prediction algorithm proposed by Drivas and colleagues which in turn would question the efficiency of inducing exon skipping to decrease phenotypic severity in patients. Larger studies relying on thorough standardized phenotypic assessments as performed for 6 patients in the study by Drivas et al. and a more nuanced classification of phenotypic severity would be helpful in confirming the reliability of the proposed exon-skipping model in predicting phenotypic outcome.

Additional issues should also be considered when thinking about controlled exon skipping as a therapeutic modality. Exon skipping may not rescue the phenotype as efficiently in genes such as CC2D2A, in which missense mutations predominate in JS/JSRD. Finally, splicing modulators may be challenging to apply in patients harbouring compound heterozygous mutations in different exons of the target gene as each splicing modulator can affect both alleles, resulting in transcripts missing multiple exons.

These points may represent limitations in the applicability or efficiency of splicing-modulation as a therapeutic option which could have been discussed by Molinari and colleagues. Nevertheless, as appropriately discussed by the authors, this avenue deserves further investigation and CEP290 is certainly the best candidate among the ciliopathy genes for such type of intervention given the high proportion of truncating mutations and the progressive nature of retinal and renal complications providing a time window for intervention. 
Is the rationale for commenting on the previous publication clearly described?

Yes

Are any opinions stated well-argued, clear and cogent?

Yes

Are arguments sufficiently supported by evidence from the published literature or by new data and results?

Yes

Is the conclusion balanced and justified on the basis of the presented arguments?

Yes

Competing Interests: No competing interests were disclosed.

Reviewer Expertise: Ciliopathies, medical genetics

I confirm that I have read this submission and believe that I have an appropriate level of expertise to confirm that it is of an acceptable scientific standard.

Reviewer Report 19 June 2017

https://doi.org/10.5256/f1000research.12479.r23066

(C) 2017 Wilson P. This is an open access peer review report distributed under the terms of the Creative Commons Attribution License, which permits unrestricted use, distribution, and reproduction in any medium, provided the original work is properly cited.

\section{Patricia D. Wilson}

Centre for Nephrology, UCL Medical School, University College London, London, UK

This clearly-written and well-argued manuscript highlights recent pertinent findings concerning mechanisms underlying exon skipping and splicing in determination of disease severity in patients with CEP290 mutations. Evidence cited is consistent with the notion that the severity of disease is inversely proportional to the level of normal or near-normal protein generated. It is suggested that phenotypic rescue, could be achieved in patients with the most common, severe nonsense mutations of CEP290 by in-frame splicing. This has important potential for personalised therapeutic intervention in the future which envisages induction of exon skipping to up regulate normal mRNA, increase near-normal protein levels and thereby reduce the severity and progression of for instance nephronopthisis, a rare disease but common cause of renal failure in children.

Is the rationale for commenting on the previous publication clearly described? Yes

Are any opinions stated well-argued, clear and cogent? 
Yes

Are arguments sufficiently supported by evidence from the published literature or by new data and results?

Yes

Is the conclusion balanced and justified on the basis of the presented arguments?

Yes

Competing Interests: No competing interests were disclosed.

Reviewer Expertise: Renal genetic disease

I confirm that I have read this submission and believe that I have an appropriate level of expertise to confirm that it is of an acceptable scientific standard.

The benefits of publishing with F1000Research:

- Your article is published within days, with no editorial bias

- You can publish traditional articles, null/negative results, case reports, data notes and more

- The peer review process is transparent and collaborative

- Your article is indexed in PubMed after passing peer review

- Dedicated customer support at every stage

For pre-submission enquiries, contact research@f1000.com 